\title{
A matemática e a potência espinosana de conhecer
}

\section{Fernando Bonadia de Oliveira}

Instituto de Educação, Universidade Federal Rural do Rio de Janeiro

fernandofilosofia@ hotmail.com

\section{Resumo}

Este artigo estabelece uma reflexão a partir do entrelaçamento de três campos do conhecimento: filosofia, matemática e educação. O núcleo da triangulação proposta é o pensamento de Bento de Espinosa, filósofo holandês do século XVII, que expôs sua filosofia à maneira dos geômetras e que considerou a dedução geométrica, por seu rigor demonstrativo, a via mais adequada ao ensino. Este texto pretende articular a matemática, tomada por Espinosa como norma de verdade impulsionadora da potência de conhecer, ao esforço por combater a ignorância, a tristeza e as superstições. A filosofia, materializada pela coerência da geometria e por sua força revolucionária no despertar da ciência moderna, se opõe ao esquema imaginário dos preconceitos alimentados por déspotas e teólogos desde o começo da era cristã. $O$ debate atravessa dimensões pedagógicas, éticas e teológico-políticas, podendo contribuir, eventualmente, para uma nova significação do ato de aprender e ensinar matemática.

Palavras-chave: Matemática. Ensino-aprendizagem. História da Educação Moderna. Filosofia da Educação Moderna. Espinosa (1632-1677).

\section{The Mathematics and the Spinozistic Potency of Knowing}

\begin{abstract}
This article establishes a reflection from the interlacing of three fields of knowledge: philosophy, mathematics and education. The core of the proposed triangulation is the thought of Baruch Spinoza, Dutch philosopher of the XVIIth century who expounded his philosophy in the manner of the geometers and who considered the geometrical deduction, because of its demonstrative rigor, the most adequate way to teaching. This text aims to articulate the mathematics, taken by Spinoza as a norm of truth that boosts the potency of knowing, to the effort to combat ignorance, sadness and superstitions. Philosophy, materialized by the coherence of geometry and by its revolutionary power in the awakening of modern science, opposes itself to the imaginary scheme of prejudices fostered by despots and theologians since the beginning of the Christian age. The debate crosses pedagogical, ethical and theological-political dimensions, and it can eventually contribute to a new signification of the act of learning and teaching mathematics.
\end{abstract}

Keywords: Mathematics. Teaching-learning. History of Modern Education. Philosophy of Modern Education. Spinoza (1632-1677). 


\section{Uma filosofia demonstrada segundo a ordem geométrica}

"O que mais faltou à filosofia foi a precisão. Os sistemas filosóficos não são talhados na medida da realidade em que vivemos. São largos demais para ela”. Assim resumiu Henri Bergson (2006, p. 4), filósofo contemporâneo francês, em uma de suas conferências, o grande desafio histórico dos sistemas filosóficos. Espinosa, segundo Bergson (2007, p. 29), trouxe à filosofia uma concepção matemática do mundo substancialmente nova, facilmente alcançada por aquele que "acompanha com precisão a verdadeira natureza das proposições matemáticas e, em particular, da matemática cartesiana”.

Espinosa viveu nos seiscentos, em pleno século da geometria ${ }^{1}$, quando a matemática deixou o posto estrito de uma ciência entre outras, para se tornar a mathesis universalis (a matemática universal) de todo o saber buscado em números, figuras, astros, sons ou qualquer outro objeto relacionado às noções de ordem e medida. É isto o que se lê na quarta das Regras para a direção do espírito de Descartes (1999, p. 84). Antes de Descartes, Galileu Galilei dissera que a filosofia estava escrita no grandíssimo livro que é o universo, livro que "não pode ser entendido se não se aprende a entender a língua, e a conhecer os caracteres nos quais está escrito". Para ele, “os caracteres são os triângulos, círculos, e outras figuras geométricas, sem cujos meios é humanamente impossível entender uma só palavra” (GALILEI, 1987, p. VIII-IX).

O tempo de Descartes e Espinosa é de cultivo da matemática como um território próspero ao desenvolvimento de obras filosóficas ${ }^{2}$, afinal, na condição de disciplina, este saber foi revalidado naquele século com autenticação institucional da Igreja. Basta lembrar a Quaestio de certitudine mathematicarum que agitou os jesuítas e pensadores da Igreja no século XVII. De início, a “Questão sobre as certezas matemáticas" colocou em xeque a concepção de que a matemática fosse, de fato, uma disciplina certa e evidente. Tanto o jesuíta italiano Giuseppe Biancani (1566-1624), que compôs o De Natura Mathematicarum Dissertatio (1615), quanto o jesuíta português João Delgado (15531612) reivindicaram que a matemática era autêntica e continha as características principais da ciência de tipo aristotélico, sendo, portanto, uma ciência legítima ${ }^{3}$.

Diante de tamanha aceitação e disseminação da matemática pela Europa - da Holanda a Portugal -, não é de causar assombro que Galileu demonstrasse a realidade das coisas naturais pela

\footnotetext{
${ }^{1}$ Paola Basso (2004, p. 13), em Il secolo geométrico, sustenta que o "século da geometria na filosofia" se estendeu de 1677, ano da publicação da Ética de Espinosa, até 1781, quando foi publicada a Crítica da Razão Pura de Kant.

${ }^{2}$ Ainda segundo Basso (2004, p. 11), o século XVII já se iniciou com uma discussão avivada em torno da geometria em terreno filosófico, mas veio a ser com a obra de Espinosa (em 1677) que, realmente, ela ficou definitivamente firmada.

${ }^{3} \mathrm{O}$ debate sobre a certeza das matemáticas se resolveu no âmbito da Igreja, mas, fora dela, questões em torno deste assunto não pararam de aparecer ao longo dos seiscentos (AUDIÉ, 2005, p. 74-79). Sobre Quaestio de certitudine mathematicarum, ver, em especial, Carolino (2006) e Chaui (1999, p. 642). Sobre este debate fora dos termos da Quaestio, ver Schöttler (2012).
} 
matemática, que Descartes geometrizasse a filosofia primeira (a Metafísica ${ }^{4}$ ), que Hobbes aplicasse a matemática ao estudo dos corpos. De forma mais surpreendente, Espinosa encampou a geometria na filosofia entendida principalmente como prática, ou seja, na ética ${ }^{5}$. Assim como Espinosa, todos aqueles outros pensadores também viveram, em certa medida, em busca da precisão em filosofia, isto é, daquele ajuste exato entre o pensamento e a realidade, como sugeriu Bergson. Mas, de acordo com o próprio Bergson, foi o autor da Ética quem tratou os principais temas da filosofia (a relação possível-real, causa-efeito, infinito-finito) de um modo "essencialmente" matemático. Os leitores dotados dos saberes da matemática podem ser, efetivamente, os mais aptos a acompanhar a longa cadeia de deduções da filosofia de Espinosa, afinal, os exemplos prediletos do filósofo envolvem esta matéria. Por outro lado, os leitores dotados de conhecimentos filosóficos e capazes de compreender, por intermédio do estudo sistemático de Descartes, a matemática do século XVII, também podem ter facilidade em apreender como, para Espinosa, conhecer é, enquanto acontecimento, a própria experiência de afetar(-se) de alegria. Seja matemático, seja filósofo, o leitor da obra espinosana esbarra, com suas virtudes próprias, no problema da matemática tomada como instrumento de ensino, como recurso didático capaz de transmitir a verdade filosófica e aumentar a potência de agir e de pensar.

Este artigo tem como objetivo mostrar o que significa, para Espinosa, tomar a matemática como "norma de verdade" contra o preconceito e a superstição que sempre impuseram ao ser humano a tristeza e o medo. Posteriormente, pretende evidenciar a diferença entre o recurso à geometria em Descartes e em Espinosa, expondo a divergência nos respectivos usos deste saber para o ensino da filosofia. Por último, tem em vista esclarecer a exemplaridade da matemática como conhecimento, bem como o valor afetivo e intelectivo de seu aprendizado.

\section{Espinosa, a matemática e as matemáticas}

O pensamento filosófico de Bento de Espinosa, em um sentido especialíssimo, tem na matemática sua espinha dorsal: ela é a fábrica, isto é, a estrutura de uma monstruosa filosofia exposta minuciosamente em ordem geométrica, a Ética, ou por completo, Ética demonstrada segundo a ordem geométrica. Esta obra espinosana é dita monstruosa para o bem e para o mal, ou seja, tanto pelo rigor assustador que se aproxima em exatidão das mais férteis projeções de Euclides, quanto

\footnotetext{
${ }^{4} \mathrm{O}$ termo "metafísica" envolve uma pluralidade de significados. No entanto, tomada como "filosofia primeira", no século XVII, a palavra delimita o campo da filosofia que estuda o Ser e o conhecimento humano dos seres. A metafísica envolve o ente e suas afecções, isto é, a Substância (Deus) ou seus modos e modificações.

5 "Ética", a rigor, é o campo da chamada "filosofia prática". Em Espinosa, a Ética (obra) foi várias referida por ele como a sua Philosphia, isto é, o conjunto todo de sua filosofia.
} 
pelo conteúdo amaldiçoado que contém em suas definições, axiomas, postulados, proposições, demonstrações, corolários, escólios, lemas, explicações, prefácios e apêndices. Esta, porém, não foi a única obra que Espinosa redigiu em conformidade com a ordem geométrica.

O Breve tratado sobre Deus, o homem e seu bem-estar, considerado para todos os fins como o esboço da Ética, apresenta um interessante apêndice geométrico, no qual o autor demonstra as principais teses de sua metafísica e de sua teoria do conhecimento. Os Princípios da Filosofia Cartesiana, a única obra que Espinosa publicou em vida com seu nome na capa, contêm as principais teses de Descartes sobre a metafísica e a epistemologia, todas demonstradas ordine geométrico ${ }^{6}$. Sólidos argumentos indicam que Espinosa delineou (sem concluir) uma gramática da Língua Hebraica inteiramente demonstrada com o rigor e a disposição dos geômetras (SANTIAGO, 2014, p. 75-104). Conforme recorda um importante comentador francês de Espinosa, isso tudo, apesar de já ser muito, nem de longe pode esgotar o manancial de fluxos matemáticos do pensamento espinosano: há inúmeras cartas e referências objetivas à matemática na maioria de suas obras (MOREAU, 2005, p. 8). A maior parte dos comentadores parece admitir que todas as obras de Espinosa seguem o método geométrico, embora apenas algumas se expressem propriamente segundo a disposição de texto geométrico. De acordo com Emanuel Fragoso (2011, p. 116-117), uma vastidão de comentadores reconhece que nenhum filósofo antes de Espinosa, e nenhum filósofo depois dele, aplicou a geometria à filosofia em toda sua integralidade ${ }^{7}$.

Curioso é que, diferentemente de Descartes, Pascal, Leibniz, Tschirnhaus e Huygens, Espinosa não era propriamente um matemático, pelo menos não no sentido em que o século XVII atribuía a este perfil. Fabrice Audié registra o consenso existente em torno da afirmação de que Espinosa não era um matemático em nenhum sentido possível da palavra. Com razão, discorda da posição contrária do estudioso holandês Win Klever, que supõe em Espinosa um "matemático qualificado" (AUDIÉ, 2005, p. 41-46). O comportamento verdadeiramente matemático de Espinosa residia na aceitação da consistência dedutiva das operações matemáticas e na aquisição da habilidade

\footnotetext{
${ }^{6}$ Os Princípios da Filosofia Cartesiana foram originalmente apresentados na forma de ditado para um aluno particular que tinha interesse em conhecer o cartesianismo. Trata-se do aluno Iohannes Caseário (cf. ESPINOSA, 2015b, p. 270; nota n. 7). Até onde sabemos, Espinosa lecionava particularmente, em sua casa, também para muitos outros estudantes holandeses (BUYSE, 2013, p. 45-46).

${ }^{7}$ Em seu estudo, Fragoso reúne as posições de Kaplan, Wolfson e Gueroult (importantes comentadores europeus de história da filosofia moderna) que comungam em dizer que, afora com Espinosa, o emprego da geometria à filosofia não passou de tentativas ocasionais. Fragoso lista uma grande série de pensadores que, antes de Espinosa, arriscaram-se à geometria, destacando como, mais do que eles, Espinosa fez dela a carne de sua filosofia. A posição de Basso (2004, p. 12) é a mesma.
} 
construtiva com que, partindo da Matemática (ou mais detidamente de sua parte que cabe à Geometria), ele conseguiu edificar toda uma filosofia ${ }^{8}$.

A geometria da Ética oferecia ao leitor do século XVII, afinado aos estudos da obra de René Descartes, uma norma de verdade que contradizia e implodia a obscurantista teia de superstições que jorram preconceitos geralmente admitidos por todos. A matemática, tomada como contraponto efetivo aos preconceitos, já estava dada desde a disseminação do cartesianismo (DESCARTES, 2005, p. 4). Em Espinosa, no entanto, o efeito liberador da matemática é mais específico; ele permite combater não apenas os preconceitos em geral (que alimentam todas as superstições), mas, acima de tudo, facilita a eliminação do preconceito arquetípico de todos os preconceitos: o preconceito finalista. Trata-se aqui de opor forças à noção de "causa final", infiltrada entre as doutrinas filosóficas desde Aristóteles. Segundo a lógica da causalidade final, tudo o que existe na natureza tem um fim: os olhos são para ver, a chuva para umedecer, o sol para iluminar e aquecer, e assim indefinidamente. Descartes, é certo, também combateu as causas finais, mas apenas na Física, mantendo-as no sistema geral de seu sistema (DESCARTES, 2007, p. 36). O apêndice da primeira parte da Ética, que será invocado agora, dedica-se a romper radicalmente com esta forma de pensar.

Os seres humanos, segundo cogitava Espinosa, podem passar a vida inteira pensando que as tempestades e as pestes se abatem sobre os povos por ira divina, tendo como finalidade punir os pecados cometidos. Mesmo a experiência cotidiana manifestando que situações cômodas e incômodas sucedem a todos os seres humanos, indiferentemente, sejam eles pecadores ou fiéis, mesmo assim, os homens comuns não se livram do preconceito finalista. Desde sempre, escreve o filósofo, "foi-lhes mais fácil pôr esses acontecimentos entre as outras coisas incógnitas, cujo uso ignoravam, e assim manter seu estado presente e inato de ignorância, em vez de destruir toda essa estrutura (fabrica) e excogitar uma nova" (ESPINOSA, 2015a, p. 50). Buscar "asilo da ignorância" corresponde à atitude mais fácil; mais difícil é destruir a estrutura finalista criadora de preconceitos e erigir uma nova forma de conhecer. A Matemática, sustenta Espinosa, "que não se volta para fins, mas somente para essências e propriedades de figuras", mostrou ao entendimento humano "outra norma da verdade", segundo a qual os fenômenos da natureza são descritos com tal ordem e com tal evidência que qualquer necessidade de persistência na ignorância é suprimida.

É certo que, além da Matemática, há outras causas que esclarecem os homens e os libertam de preconceitos comuns, encaminhando-os ao verdadeiro conhecimento dos objetos, mas a ciência

\footnotetext{
${ }^{8}$ Audié apura, com minúcia, as fontes do repertório matemático de Espinosa que o tornaram tão hábil no manejo das argumentações matemáticas. Sabemos, pela Carta 9 do epistolário espinosano, que ele dominava profundamente as ideias geométricas de Clavius, Taquet e outros. Passagens do Breve Tratado e da Ética mostram que Espinosa dominava bem os Elementos de Euclides (AUDIÉ, 2005, p. 25-28).
} 
dos números é mesmo exemplar. A exemplaridade da matemática se caracteriza por traduzir, no entendimento de Espinosa, a melhor via para o ensino e para o aprendizado da verdadeira filosofia.

\section{A adequação da geometria ao ensino e ao aprendizado}

Descartes já havia se valido da precisão da ordenação geométrica, mas com ressalvas. Ao anunciar o projeto das Meditações metafísicas (em 1641), ele explicou aos doutores da Faculdade de Teologia de Paris que intentava provar a existência de Deus e a imortalidade da alma humana, de acordo com razões filosóficas, ou seja, pela razão natural. Ele objetivava convencer ateus e fiéis com seus argumentos, da mesma forma que ateus e fiéis podem ser convencidos igualmente das razões matemáticas pelas demonstrações euclidianas. Em seguida, contraditoriamente, ele admitiu que nem todos seriam sagazes para entender suas deduções, porque como as deduções da geometria, "são um pouco longas e pedem um espírito inteiro", "um espírito inteiramente livre de todos os prejuízos”, e que se desenlace facilmente do "comércio com os sentidos". O aprendiz da filosofia cartesiana deve, pois, ao se dedicar sobre os estudos, desvencilhar-se das sensações corporais.

A reivindicação da geometria como natureza de saber e como prática de ensino que afasta a alma dos indivíduos das impressões sensíveis, geradoras do erro, aparece sistematicamente em Agostinho, sobretudo nos escritos da juventude, como os Soliloquia, o De Quantitate Anima e o De Libero Arbitrio; com Descartes, a geometria se torna favorável ao ensino em sentido moderno; em virtude de poder ser separada e compreendida em enunciados fáceis, devida e claramente demonstrados, a geometria é um válido recurso didático; porém, em virtude da longa cadeia de razões que expõe, pede do aprendiz uma firmeza de ânimo rara de se encontrar (DESCARTES, 2005, p. 7).

$\mathrm{Na}$ resposta às segundas objeções feitas às Meditações metafísicas, Descartes concedeu o pedido que lhe foi feito para expor suas principais ideias metafísicas em ordem geométrica, através de definições, axiomas, postulados etc. Neste texto, Descartes adverte acerca de uma distinção feita por ele entre "duas coisas" relativas ao "modo de escrever dos geômetras": a ordem de demonstrar e a maneira de demonstrar. A ordem de demonstrar (justamente aquela que Descartes, segundo ele mesmo, se empenhou tanto quanto pôde para seguir em sua obra) determina que as coisas propostas em primeiro lugar devam ser conhecidas sem qualquer auxílio das coisas que delas se seguem, e que as coisas que se sigam das primeiras sejam de tal forma expostas que se demonstrem unicamente pelas coisas que as precedem. A maneira de demonstrar, por sua vez, divide-se em duas: (a) aquela que se faz pela análise ou resolução e (b) aquela que se faz pela síntese ou composição.

A análise mostra o caminho pelo qual uma coisa foi descoberta de forma metódica, revelando como os efeitos dependem das causas. Isso se processa de modo que, se o leitor seguir esta ordem e 
lançar um olhar cuidadoso sobre tudo o que ela contém, entenderá a coisa assim demonstrada com a mesma perfeição daquele que a demonstrou pela primeira vez, compreendendo a descoberta como se fosse sua. Por meio da análise, Descartes parte da dúvida metódica e, através dela, atinge sua primeira certeza, o cogito, "Penso, logo sou". É a partir desta primeira certeza que ele deduz a existência do corpo, das coisas e, enfim, de Deus.

A síntese, por sua vez, demonstra claramente o que está contido em sua conclusão. Segundo Descartes, a síntese realiza a demonstração por um caminho diferente da análise, de modo que as causas são examinadas pelos efeitos. A síntese consiste em uma longa cadeia de definições, postulados e outras etapas, com a finalidade de que, negando-lhe algumas consequências, o autor mostre como a verdade está contida nos seus antecedentes. Na maneira sintética de demonstrar, o filósofo parte primeiro da demonstração da existência de Deus para, posteriormente, demonstrar a existência do corpo e da mente. Esta dedução se processa, como foi dito, por intermédio dos recursos típicos do texto geométrico (proposições, demonstrações etc.) ${ }^{9}$.

Tanto a análise quanto a síntese merecem ressalvas relativas ao modo como são apreendidas pelos leitores. De acordo com Descartes, a análise é incapaz de convencer um leitor "teimoso" e “desatento", uma vez que, escapando-lhe a menor das coisas que ela propõe, não haverá o nexo que determina a necessidade das suas conclusões; a síntese, dada a sua natureza, consegue retirar o consentimento do leitor por mais "opiniático" e "obstinado" que ele possa ser. Não obstante, esta maneira de demonstrar não dá total satisfação aos que desejam aprender, pois não ensina o método através do qual a coisa foi descoberta. A análise foi escolhida para cumprir o itinerário das Meditações, pois parecia então ser a via "mais verdadeira" e a "mais própria ao ensino" (DESCARTES, 1983, p. 167).

Espinosa pensava de outro jeito.

A divulgação do pensamento de Descartes se deu muito próxima do momento da elaboração da filosofia espinosana. Já por esta época - poucos anos depois da morte do filósofo francês - faziase frequentemente uma leitura dogmática do cartesianismo. Diante da novidade e do impacto das descobertas científicas cartesianas, todos os estudiosos se preocupavam mais em acatar com rapidez as teses do filósofo francês do que em entendê-las devidamente (SANTIAGO, 2004, p. 10; 13). No prefácio aos Princípios da Filosofia Cartesiana de Espinosa, Luis Meyer adverte, com o consentimento do autor, que muitos indivíduos "não conseguem nem seguir por si mesmos nem exibir aos outros as coisas tratadas nesses livros, apoditicamente demonstradas". Isso porque

\footnotetext{
${ }^{9}$ Como, talvez, estas discussões possam ser novas para o leitor não especializado em questões metodológicas ligadas à filosofia moderna, recomenda-se para um entendimento mais claro deste ponto, o artigo "O papel da análise e da síntese na ordem das razões segundo Descartes", de Forlin (1998).
} 
“completamente rudes nas ciências matemáticas", eles desconhecem o método sintético pelo qual as coisas ali tratadas foram escritas, e ignoram o método analítico pelo qual tais coisas foram descobertas (MEYER, 2015, p. 35-36). Espinosa, ao propor a exposição do cartesianismo a partir da via sintética dos geômetras, tomava como sua a "opinião unânime de todos os que querem saber além do vulgo": "o método dos matemáticos para investigar e transmitir as ciências [...] é a melhor e mais segura via para indagar e ensinar a verdade"; tal método deve se desenrolar pela síntese, isto é, em um raciocínio que se apresenta a partir de "definições, postulados e axiomas" (MEYER, 2015, p. 33).

Os motivos que conduziram Espinosa à escolha da via sintética como a mais adequada para a exposição geométrica dos fundamentos do cartesianismo se apresentam prontamente quando atentamos à natureza de um texto geométrico. Um texto hieroglífico, em oposição a um texto geométrico, não oferece ao leitor os fundamentos e as premissas das quais parte e, por isso, requer estudo do tempo em que foi redigido e exige pesquisas sobre o autor que o produziu. O texto de caráter geométrico, assim como o texto euclidiano transmitido à posteridade, é diretamente entendido por qualquer leitor, afinal, antes de tudo, parte de definições, de axiomas e postulados que explicitam o real significado de seus termos. Euclides "só escreveu coisas extremamente simples e altamente inteligíveis"; seu saber pode ser ensinado sem dificuldade "a toda gente", contanto que o aprendiz tenha um domínio básico da língua do autor. Já a compreensão integral da Escritura, hieróglifo por excelência, depende do conhecimento integral do hebraico, da história de seus autores, do destino que conheceram seus livros, bem como das diversas alterações que sofreram ao longo do tempo (ESPINOSA, 2003, p. 131). Se dos Elementos se perdesse para sempre a memória do nome do autor, ainda assim o texto poderia ser perfeitamente compreendido por todos os que conhecem o essencial da língua grega. O mesmo, todavia, não se passaria com a Escritura.

Em suma, Espinosa, como Descartes, concorda que a geometria é a ordem que mais adequada aos aprendizes. Mas, afastando-se de Descartes, Espinosa afirma que é a síntese (e não a análise) a via mais fértil para o ensino da filosofia verdadeira.

Dessa forma, Espinosa tomou um caminho original na história da aplicação da matemática à filosofia. Contudo, vale indagar: o que Espinosa queria preservar ao se ater à síntese geométrica, ao contrário do que se dera com Descartes? O sentido mais amplo e geral da síntese geométrica no pensamento espinosano é o de "ordem dedutiva": a síntese apresenta-se em certa ordem dedutiva que pode ser facilmente alcançada por qualquer um, mas isso se faz com tal rigidez e precisão que passa a ser impossível ao aprendiz entender os conteúdos apenas por repetição ou por imitação (SANTIAGO, 2014, p. 91). O aprendiz aprende em uma ordem que está em conformidade com o seu próprio raciocínio, que é, na verdade, a maneira humana comum de pensar retamente. Nas palavras 
de Marilena Chaui (2003, p. 203), que resume com perfeição o papel da matemática na filosofia de Espinosa,

a matemática nos ensina o que é uma dedução completa porque oferece a concatenação completa de uma ideia, isto é, sua causa e seus efeitos [...], permite deduzir ou demonstrar a totalidade das propriedades que possui e, portanto, seus nexos necessários com todas as outras de que depende ou que dela dependem; [...] a geometria é a maneira exemplar de apresentar essa articulação dedutiva imanente.

O recurso à geometria impede o pensamento de proceder por abstrações, isto é, de retirar de uma causa distante (e separada do efeito) o fundamento de uma explicação do real. O emprego dos recursos geométricos garante a lisura do pensar filosófico. Além deste benefício sublime, concedido a todos os que querem conhecer as matérias da Filosofia na ordem e no modo como devem ser conhecidas, a geometria guarda ainda uma última utilidade: ela não contraria, mas concorda com a experiência; as demonstrações geométricas, na obra de Espinosa, estão "talhadas", como disse Bergson, "na medida da realidade em que vivemos".

\section{A matemática e a potência de conhecer}

No final do curto trajeto percorrido, convém notar que a matemática corresponde, no entender de Espinosa, ao caminho mais recomendado ao aprendizado e ao ensino da filosofia verdadeira, não só porque extrinsecamente concorda com a realidade, mas porque intrinsecamente se constitui como concatenação imanente e concreta da causa nos efeitos. A matemática não só expõe o verdadeiro, mas demonstra como ele se produz e devém verdadeiro, oferecendo a gênese do conhecido. Como recorrentemente lembrou Deleuze (2002, p. 55-62; 2003, p. 75-91) em provocantes escritos e aulas, de acordo com Espinosa, cada vez que a mente conhece, ela experimenta uma alegria, ou seja, um aumento da potência de pensar. A alegria da mente ao conhecer é o maior afeto que ela pode experimentar ${ }^{10}$ porque afasta as tristezas do ânimo derivadas de medos e pavores da mente relativamente aos castigos infernais ou coisas deste tipo, falsamente decretadas pelo preconceito finalista e comandadas politicamente pela religião.

Na contramão dos ptolomaicos que tiveram de curvar a matemática para adequá-la aos fatos astronômicos (na medida em que os cálculos não conferiam com a realidade das órbitas celestes), Espinosa, seguindo a cadeia dedutiva da Ética, descreveu a realidade dos fenômenos tal como ela é experimentada pelos seres humanos. No prefácio à terceira parte da Ética, dedicada ao estudo da natureza e da origem dos afetos, Espinosa anuncia: “Tratarei [...] da natureza e das forças dos Afetos

\footnotetext{
10 Os afetos que têm origem na razão são os mais potentes (Ética V, Proposição 7); conhecer a natureza é o maior conhecimento e o maior bem que a mente pode experimentar (Ética IV, Proposição 28) (ESPINOSA, 2015a, p. 390; 412).
} 
e da potência da Mente sobre eles com o mesmo Método com que tratei de Deus e da Mente nas partes precedentes". E conclui sinceramente: “considerarei as ações e apetites humanos como se fosse questão de linhas, planos ou corpos" (ESPINOSA, 2015a, p. 210). O que se encontra nas deduções desta terceira parte da obra não difere - insistamos - mas coincide com a experiência. Nas páginas da Ética, os textos contidos em escólios e apêndices atestam isso, já que guardam explicações que, à parte da rigorosa cadeia dedutiva, evidenciam os argumentos ali oferecidos de forma acessível à experiência comum que temos no mundo.

Os afetos principais concernentes aos seres humanos são precisamente dispostos no livro, em um apêndice geométrico especial, sob a forma de definições. A alegria - escreve o filósofo - se dá quando passamos de uma potência menor de agir e de pensar para uma potência maior; a tristeza, por outro lado, ocorre quando passamos de uma potência maior a uma potência menor de agir e de pensar. Esta passagem ou transição (transitio, escreve Espinosa) se dá sempre no contato que mantemos com aquilo que está fora de nós, pois dependemos da exterioridade para perseverar na existência. Essa disposição interna, por meio da qual agimos e pensamos no mundo, define a nossa potência. As coisas pelas quais sentimos alegria serão amadas por nós e as julgaremos boas tanto quanto forem úteis para nossa permanência na existência e para o aumento de nossa potência; as coisas pelas quais sentimos tristeza serão por nós odiadas, e as reputaremos más, posto que estão ligadas a prejuízos para nossa continuidade no existir. Viver, para Espinosa, é uma variação contínua da potência, ao menos de acordo com modo pelo qual interpreta Deleuze.

Deleuze, em uma de suas aulas, a fim de explicar com clareza a dinâmica espinosana dos afetos, se coloca no lugar de um sujeito que encontra Pedro (indivíduo que lhe causa tristeza) e, logo em seguida, Paulo (alguém que lhe causa alegria). "Quando vejo Pedro, que me desagrada, a ideia de Pedro me é dada; quando vejo Paulo, que me compraz, a ideia de Paulo me é dada". Prosseguindo mais detidamente no exemplo, ele observa:

Quando eu passo da ideia de Pedro à ideia de Paulo, eu digo que minha potência de agir é aumentada; quando eu passo da ideia de Paulo à ideia de Pedro, eu digo que minha potência de agir é diminuída. Isso equivale a dizer que quando eu vejo Pedro, sou afetado de tristeza; quando eu vejo Paulo, sou afetado de alegria. E sobre essa linha melódica de variação contínua constituída pelo afeto, Spinoza irá determinar dois polos, alegria-tristeza, que serão para ele as paixões fundamentais: a tristeza será toda paixão, não importa qual, que envolva uma diminuição de minha potência de agir, e a alegria será toda paixão envolvendo um aumento de minha potência de agir. Isso permitirá que Spinoza, por exemplo, realize uma abertura em direção a um problema moral e político muito fundamental, que será sua própria maneira de estabelecer o problema político: como acontece que as pessoas que têm o poder, não importa em que domínio, tenham necessidade de afetar-nos de uma maneira triste? (...) Inspirar paixões tristes é necessário ao exercício do poder. E Spinoza diz, no Tratado teológico-político, que esse é o laço profundo entre o déspota e o sacerdote: eles têm necessidade da tristeza de seus súditos (DELEUZE, 2003, p. 172). 
A transcrição da aula de Deleuze, conquanto seja longa, nos concede uma leitura pertinente da dinâmica afetiva do espinosismo, isto é, da necessária e constante variação de nossa potência ao longo da vida, a cada instante da vida. Mais que isso, oferece-nos uma problematização contendente acerca do modo pelo qual a promoção da tristeza é consolidada em um projeto político, ou melhor, teológico-político. Os ditadores e os sacerdotes se interessam pela manutenção de uma massa ignorante e crente em toda sorte de castigos terríveis ou premiações suntuosas nos céus. Ditadores e sacerdotes (assim como todos os que agem tiranicamente) se esforçam, tanto quanto podem, por desviar os seres humanos do reto conhecimento das coisas e da alegria que elas despertam quando são conhecidas.

Não foi sem razão que, durante o século da descoberta da matemática como mathesis universalis, os matemáticos (ou os pensadores ligados a procedimentos matemáticos) tenham sido tão perseguidos pela Inquisição Romana. Giordano Bruno e Galileu Galileu foram condenados. Até mesmo Descartes teve sua obra proibida cerca de treze anos depois de sua morte (BUYSE, 2013, p. 61). Espinosa, por sua vez, teve a obra posta no Index Librorum Prohibitorum, o índice dos livros proibidos pela Igreja. Evidentemente, a condenação epistemológica, moral e política dos escritos destes filósofos se relacionou a problemas advindos não só do choque entre suas teorias e certas afirmações bíblicas, mas também da célebre proibição aristotélica da metábase ${ }^{11}$. Entretanto, o fato de justamente estes - os mais matemáticos dos filósofos - terem sido condenados no momento em que a matemática anunciava sua virtude universal, revela o quanto o conhecimento foi coibido.

Como se pode depreender da explicação dada por Deleuze, não há em Espinosa cisão entre os domínios da razão e da emoção. O conhecimento, aliás, sendo o afeto mais potente dentre os afetos, torna aquele que conhece alguém que frui a virtude. $\mathrm{O}$ conhecimento da natureza, mediado pela matemática - a norma de verdade que livra os seres humanos de uma vida associada à prática do preconceito e do medo - é o mais adequado meio pelo qual mente humana pode conceber as coisas.

Depois de compreendermos a prática de Espinosa na produção de um conhecimento causal, demonstrável e verdadeiro, tentamos evidenciar que aprender matemática e aprender pela matemática (no tempo de Espinosa e em conformidade com os quadros teóricos de seu pensamento), é aprender a precisão em filosofia. Matematizar o mundo dos afetos, como fez Espinosa, não significa retirar dos afetos sua espontaneidade e sua essência enquanto transições humanas da potência, mas entender qual é a dinâmica das emoções e, afinal, como podemos, pela mediação deste entendimento, aumentar cada vez mais a alegria que sentimos, e afastar progressivamente a tristeza da qual padecemos.

\footnotetext{
${ }^{11}$ A metábase, segundo Aristóteles, consistia no procedimento de estender indiscriminadamente os princípios de certa ciência a outra.
} 


\section{Referências bibliográficas}

AUDIÉ, F. Spinoza et les mathématiques. Paris: PUF, 2005.

BASSO, P. Il secolo geometrico - la questione del metodo matematico in filosofia da Spinoza a Kant. Milano: La Lettere, 2004.

BERGSON, H. O pensamento e o movente. Tradução: Bento Prado Neto. São Paulo: Martins Fontes, 2006.

BERGSON, H. Spinoza. In: LECERF, Eric; KOHAN, Walter (orgs). Imagens da imanência: escritos em memória de H. Bergson Belo Horizonte, Autêntica, 2007.

BUYSE, F. Spinoza, Boyle, Galileo: was Spinoza a strict mechanical philosopher? Intellectual History Review, n. 22, mar. 2013.

CAROLINO, J. João Delgado SJ e a Quaestio de certitudine mathematicarum em inícios do século XVII. Revista Brasileira de História da Matemática, n. 11, p. 17-49, abr./set. 2006.

CHAUI, M. Nervura do Real (Volume I). São Paulo: Companhia das Letras, 1999.

DELEUZE, Gilles. Espinosa - filosofia prática. Tradução: Daniel e Fabien Lins. São Paulo: Escuta, 2002.

DELEUZE, Gilles. En medio de Spinoza. Tradução: Cactus Editorial. Buenos Aires: Cactus, 2003. DESCARTES, R. Regras para a direção do espírito. Tradução: Maria Galvão. São Paulo: Martins Fontes, 1999.

DESCARTES, R. Objeções e respostas. Tradução: Bento Prado Jr. \& J. Guinsburg. São Paulo: Abril, 1983, Os Pensadores.

DESCARTES, R. Meditações metafísicas. Tradução: Maria Galvão. São Paulo: Martins Fontes, 2005.

DESCARTES, R. Princípios da Filosofia. Tradução: Ana Cotrim \& Helena Burati. São Paulo: Rideel, 2007.

ESPINOSA, B. Tratado Teológico-Político. Tradução: Diogo Pires Aurélio. São Paulo: Martins Fontes, 2003.

ESPINOSA, B. Ética. Tradução: Grupo de Estudos Espinosanos. São Paulo: Edusp, 2015a.

ESPINOSA, B. Princípios da Filosofia Cartesiana; Pensamentos Metafísicos. Tradução: Homero Santigo \& Luís Oliva. Belo Horizonte: Autêntica, 2015b.

FRAGOSO, E. O método geométrico em Descartes e Espinosa. Fortaleza: Editora da UECE, 2011.

GALILEU, G. O Ensaiador. Tradução: Helda Barraco et alii. São Paulo: Nova Cultural, 1987.

MEYER, L. Prefácio. In: ESPINOSA, Bento. Princípios da Filosofia Cartesiana; Pensamentos Metafísicos. Tradução: Homero Santigo \& Luís Oliva. Belo Horizonte: Autêntica, 2015.

MOREAU, P-F. Préface. In: AUDIÉ, Fabrice. Spinoza et les mathématiques. Paris: PUF, 2005.

SANTIAGO, H. Espinosa e o cartesianismo - o estabelecimento da ordem nos Princípios da Filosofia cartesiana. São Paulo: Humanitas, 2004.

SANTIAGO, H. Geometria do instituído - estudo sobre a gramática hebraica espinosana. Fortaleza: Editora da UECE, 2014. 
SCHÖTTLER, T. From causes to relations: the emergence of a non-aristotelian concept of geometrical proof out of the Quaestio de certitudine mathematicarum. Society and Politics, vol. 6, n. 2 (12); nov. 2012, p. 29-47.

Artigo convidado 